This work is licensed under a Creative Commons Attribution 4.0 International License.

Ovaj rad dostupan je za upotrebu pod međunarodnom licencom Creative Commons Attribution 4.0.

https://doi.org/10.31820/f.31.2.13

Zdravko Šolak

\title{
REČCA ZAR U KRLEŽINOJ ZBIRCI PRIČA HRVATSKI BOG MARS
}

dr. sc. Zdravko Šolak, Visoka poslovna škola, zdrsolak@yahoo.com, Novi Sad

izvorni znanstveni članak

UDK 821.163.42.09Krleža, M.-32

811.163.42'38Krleža, M.

rukopis primljen: 27. lipnja 2019; prihvaćen za tisak: 5. prosinca 2019.

Posmatran je ukupan skup javljanja rečce zar u Krležinoj zbirci priča Hrvatski bog Mars. Pri osnovnom pregledu tog skupa jasno su uočene kvantitativne karakteristike: neravnomeran raspored reči zar po pojedinim pričama u zbirci, pojava mesta koncentracije na kojim javljanja rečce zar dolaze u blizini jedno drugog, zatim asimetrija javljanja kada je u pitanju raspored javljanja rečce zar u govoru pojedinih likova u priči. Tipična situacija u čijem je opisu upotrebljena rečca zar jeste oficirsko obraćanje vojnicima. Ona je doprinela da se u tom obraćanju iskažu: prekor, ruženje, uvrede, ispoljavanje besa, psovke, pretnje. Rečca zar se takođe javljala i u unutrašnjim monolozima, kao i u razgovorima koje vojnici vode među sobom. Upotreba rečce zar znatno je doprinela karakterizaciji likova kada su u pitanju oficiri. Njena upotreba omogućila je da u opisu do izražaja dođe živost razgovora koje vode vojnici, kao i da se opiše preispitivanje kojem su u trenucima osame podložni i oficiri i vojnici.

Ključne reči: rečca zar; M. Krleža; Hrvatski bog Mars; dijalog; leksičko ponavljanje; kohezija

\section{Uvod}

Ispitaćemo kako je Miroslav Krleža (1893-1981) u zbirci priča Hrvatski bog Mars koristio rečcu zar. Povod za takvu analizu bio je znatan intenzitet 
njene upotrebe uočljiv već pri čitanju dela s uobičajenom pažnjom. I druge kvantitativne osobine javljanja rečce zar otkrivene osnovnim pregledom teksta, ukazivale su na to da Krležina upotreba rečce zar u pojedinim pričama i u zbirci u celini zaslužuje pažnju i analizu.

O poreklu rečce zar u jednom zapažanju iz ranijih godina rečeno je „da je postanje reči zar tamno" (Maretić 1931: 475). U novijim istraživanjima ima nepodudarnih stavova u lingvističkoj literaturi: obrazlaže se pretpostavka „da je rečca zar hibridnog, slovensko-turskog porekla” (Vlajić 2016: 80), kao i da je u pitanju „balkanizam” arapskoga porekla (Pranjković 2012: 35).

Kada je reč o samoj upotrebi navodi se da „upitna rečca zar izražava čuđenje" (Piper i Klajn 2013: 215). ${ }^{1}$ Rečenice u kojima se ona koristi izgovaraju se obično s upitnom, a ponekad i sa uzvičnom intonacijom. Ukoliko je intonacija upitna, odgovor se, potvrdan ili odričan, prilagođava formi pitanja. Osim toga, pitanja u kojim se rečca zar javlja često su retorska i na njih se ne odgovara niti se odgovor očekuje. ${ }^{2}$

Kada je reč o književnoj upotrebi rečce zar i o njenom javljanju u delu jednog pisca, pažnju je moguće usmeriti kako na intenzitet njenog korišćenja tako i na funkcije koje ona dobija u tekstu. U ranijem istraživanju (Šolak 2018) pokazalo se da je potpuniju analizu upotrebe rečce zar u delu Ive Andrića (1892-1975) bilo moguće potpunije sagledati tek pošto su se u obzir uzeli, ne samo rečenica u kojoj se ona javlja, već i širi kontekst, epizoda događaja o kom se pripoveda, a ponekad i priča u celini. ${ }^{3}$

U ovom radu, sledeći metod potpunog obuhvata izdvojene su sve rečenice iz Krležine zbirke priča, zatim su ispitane kvantitativne odlike rasporeda rečce zar u pojedinim pričama i u celoj zbirci. Potom se pažnja usmerila na objašnjenje uočene znatne neravnomernosti tog rasporeda. Postavljena je preliminarna hipoteza o jakoj uslovljenosti kao što je postojanje tipične situacije u kojoj se nalaze likovi i odnos među njima. Hipoteza je proveravana ispitivanjem odlika rečenica u kojima se rečca zar pojavljuje.

1 U rečnicima iz ranijih godina navođeno je da reč zar može da znači i valjda, možda. (Matica srpska 1967, knjiga II: 202).

2 „Većina zar pitanja su u stvari retorska, na koja se ne očekuje odgovor, pogotovu ona koja izražavaju iznenađenje, nevericu, čuđenje." (Mrazović 2009: 506).

3 U pričama i romanima Ive Andrića rečca zar upotrebljavana je štedljivo. Na mestima na kojim se ona javlja obično se u pripovedanju o nekom događaju stiglo do tačke kulminacije (Šolak 2018). 


\section{Osnovni pregled}

\subsection{Korišćeni izvori}

U zbirci priča Hrvatski bog Mars rečca zar upotrebljena je 65 puta. Imamo u vidu izdanje objavljeno kao šesti svezak u okviru piščevih sabranih dela (Krleža 1962). U tom izdanju na trinaest mesta pojavljuje se rečca zar $\mathrm{u}$ rečenicama u kojim se u prethodnom izdanju zbirke u sastavu sabranih dela kod istog izdavača (Krleža 1955), kao i u ranijim izdanjima zbirke, nalazila druga upitna reč ili kratak izraz (što, šta, pa šta, je li). ${ }^{4}$ Sa promenom iz 1962. godine štampana je zbirka priča i u jubilarnom izdanju odabranih dela u izboru samog autora (Krleža 1973), kao i kasnija izdanja zbirke kod istog izdavača (Krleža 1982, 1988c). Isto tako je i u beogradskim izdanjima (Krleža 1973a; 1977a). U splitskom izdanju iz 1988. godine promene su takođe unete (Krleža 1988a). Ako se izuzme jedna omaška, rečca zar se pojavljuje i u elektronskom izdanju zbirke priča Hrvatski bog Mars na mestima na kojim se našla u izdanju iz 1962. godine. ${ }^{5}$ Treba međutim napomenuti da je i posle 1962. godine bilo izdanja u kojima nisu unete izmene koje se odnose na rečcu zar. Takva izdanja objavili su sarajevski izdavači „Veselin Masleša” (Krleža 1984, 1988) i „Svjetlost” (Krleža 1963, 1967, 1973, 1977, 1980 i 1989). ${ }^{6}$

\subsection{Odlike rasporeda rečce zar u zbirci priča}

Već pri osnovnom pregledu ukupnog broja javljanja rečce zar uočena su tri jasno ispoljena svojstva. Prvo, različita je učestalost javljanja u pojedinim pričama, sa izraženim krajnostima: rečca se uopšte ne javlja u priči Bitka kod Bistrice Lesne, u priči Baraka pet be javlja se jednom, a učestala je u priči Tri domobrana (dvadeset i jedno javljanje) i u priči Kraljevska ugarska domobranska novela (dvadeset i pet javljanja). Drugo, rečca zar česta je u rečenicama kojima

\footnotetext{
$4 \mathrm{U}$ tabeli 2 u prilogu ovog rada navedene su rečenice u koje su unete takve izmene.

5 Rečenica: „Za njim jedna probdjevena noć na vlaku, [...].” (Krleža 1962: 390) pojavila se izmenjena: „Zar njim je jedna probdjevena noć na vlaku, [...].” (Krleža, Hrvatski bog Mars, www. eLektire.škola.hr). Pristup 20. 06. 2019.

6 Na osnovu navedenih tiraža (imajući u vidu izdanja u kojima su podaci o tiražu navedeni), procenjujemo da je ukupan tiraž kod oba izdavača bio 25-30 hiljada primeraka. Pada u oči činjenica da su se u istom gradu, Sarajevu, iste 1988. godine, pojavila dva nepodudarna izdanja knjige Hrvatski bog Mars, jedno u izdanju "Oslobođenja”, i drugo, u izdanju „Veselina Masleše”.
} 
se oficiri obraćaju potčinjenim vojnicima ili dok razmišljaju o poslu kojim se bave. Treće, javljaju se mesta koncentracije u priči. To su delovi teksta u kojima se više primera upotrebe rečce zar nalaze u blizini jedan drugog.

a) Pregled ukupnog broja javljanja rečce zar u pojedinim pričama, sastavljen prema izdanju (Krleža 1962), sadržan je u tabeli 1. Dužina priča (druga kolona) iskazana je brojem strana. U trećoj koloni je broj javljanja rečce zar, a u poslednjoj koloni je odnos broja strana i broja javljanja. Imajući u vidu odnos u poslednjoj koloni moguće je zaključiti da je raspored rečce zar u knjizi posve neravnomeran. Pregledom je utvrđeno da ni u jednoj priči nema rečenica u kojima se rečca zar pojavljuje više od jednom. Tako je broj javljanja rečce zar jednak broju javljanja „zar-rečenica”.

Tabela 1. Rečca zar u zbirci priča Hrvatski bog Mars

\begin{tabular}{|l|c|c|c|}
\hline \multicolumn{1}{|c|}{ priča } & $\begin{array}{c}\text { dužina priče, } \\
\text { stranica }\end{array}$ & $\begin{array}{c}\text { broj javljanja } \\
\text { rečce } \text { zar }\end{array}$ & $\begin{array}{c}\text { broj strana/ } \\
\text { broj javljanja }\end{array}$ \\
\hline Bitka kod Bistrice Lesne & 36 & 0 & - \\
\hline $\begin{array}{l}\text { Kraljevska ugarska } \\
\text { domobranska novela }\end{array}$ & 134 & 25 & 5,4 \\
\hline Tri domobrana & 86 & 21 & 4,1 \\
\hline Baraka pet be & 19 & 1 & 19,0 \\
\hline Domobran Jambrek & 40 & 7 & 5,7 \\
\hline Smrt Franje Kadavera & 47 & 7 & 6,7 \\
\hline Hrvatska rapsodija & 33 & 4 & 8,2 \\
\hline
\end{tabular}

b) Znatan broj javljanja rečce zar u najužoj je vezi s malim brojem likova. Tu su, pre svega, četiri oficira: kapetani Jugović i Ratković, pukovnik Wallenstein i poručnik Lulić. Rečca zar javlja se u njihovom obraćanju potčinjenim vojnicima, a ponekad i u njihovim mislima o poslu kojim se bave, o vojničkom pozivu. U Kraljevskoj ugarskoj domobranskoj noveli svih dvadeset i pet javljanja reči zar povezana su sa glavnim likom, satnikom Jugovićem. Dvadeset i tri javljanja sadržana su u njegovim direktnim obraćanjima vojnicima, a dva se javljaju u Jugovićevom monologu dok razmišlja o svom pozivu i ljudima koji su mu potčinjeni. Na sličan način petnaest javljanja rečce zar u priči Tri domobrana povezano je s jednim likom, kapetanom Ratkovićem, a tri s pukovnikom Wallensteinom. Od

7 O upotrebi izraza „zar-rečenica” videti: (Šolak 2018: 179). 
sedam pojavljivanja u priči Domobran Jambrek, četiri su sadržana u replikama poručnika Lulića koji razgovara sa svojim vojnicima.

c) U osnovnom pregledu lako se uočavaju tačke koncentracije rečce zar u tekstu. U pitanju su mesta u priči na kojima se rečca zar pojavljuje u rečenicama koje su u blizini jedna druge. ( $\mathrm{Za}$ označavanje mesta koncentracije rečce zar korišćen je kriterijum: tri ili više javljanja u tekstu čija dužina nije veća od trideset redova štampanog teksta.) Tako je u Kraljevskoj ugarskoj domobranskoj noveli na strani 48-49 rečca zar upotrebljena pet puta u dvadeset i pet redova teksta. U istoj priči na strani 147 upotrebljena je šest puta u osam redova teksta. U priči Tri domobrana na stranicama 260-261 javlja se četiri puta u trideset redova teksta. U priči Domobran Jambrek dve su tačke koncentracije: jedna na stranicama 308309 sa tri javljanja u pet redova teksta, i druga na strani 331, tri javljanja u osam redova teksta. Kada su u pitanju mesta koncentracije frekventnu upotrebu rečce zar čitalac će verovatno zapaziti pri čitanju s uobičajenom pažnjom. U pitanju je leksičko ponavljanje (lexical repetition) koje se na mestima koncentracije ponekad javlja u rečenicama koje dolaze jedna za drugom te tako poprima kontaktni vid.

Upotreba rečce zar u Krležinoj zbirci priča Hrvatski bog Mars odlikuje se veoma izraženom asimetrijom javljanja. Znatno je različit broj javljanja u pojedinim pričama (tabela 1 ). Asimetrija dolazi do izražaja i ako se imaju u vidu delovi priča u kojim se rečca zar javlja, odnosno ne javlja, kao i u pogledu likova koji rečcu zar koriste, odnosno ne koriste u svom govoru. Asimetrija se najjače ispoljila u priči u Kraljevskoj ugarskoj domobranskoj noveli: sva javljanja su povezana s jednim likom, satnikom Jugovićem. I govorna situacija u kojoj se nađu osobe čija je pozicija u lancu vojničke hijerarhije različita, odlikuje se asimetrijom: rečca zar javlja se u govoru onoga ko naređuje i kontroliše, a nema je u govoru onoga ko sluša i izvršava naređenja. Uočljive asimetrije upućuju na početnu hipotezu istraživanja prema kojoj je rečca zar dobijala posebnu ulogu u priči u zavisnosti od teme i događaja o kojima se pripoveda, likova koji uzimaju udela u tim događajima i situacija u kojima se likovi nalaze.

Najveći broj upotreba rečce zar u zbirci Hrvatski bog Mars vezana je za opis sličnih situacija iz vojničkog života. Ona se javlja u opisima razgovora koje vode vojnici među sobom. A mnogo češće upotrebljena je u opisima situacija koje su vezane za samu službu, za obuku i obavljanje vojničkih zadataka. To su situacije u kojim do izražaja dolazi tipičan odnos između nadređenog i podređenog uređen strogom hijerarhijom. Rečca zar javljala 
se u obraćanjima jedne osobe drugoj ili drugim osobama (55 puta), kao i u unutrašnjim monolozima pojedinih likova (10 puta).

Istražujući odlike upotrebe rečce zar u pričama iz zbirke Hrvatski bog Mars potražićemo u ovom radu odgovore na sledeća pitanja. Imaju li rečenice u kojim je rečca zar upotrebljena neke zajedničke odlike? Da li se odlike upotrebe reči zar mogu dovesti u vezu s temom priča?

\section{Rečca zar u obraćanju starešine podređenom vojniku}

Rečcu zar u svojim obraćanjima podređenom upotrebili su oficiri: kapetani Jugović i Ratković, pukovnik Wallenstein i poručnik Lulić. To su likovi iz priča: Kraljevska ugarska domobranska novela, Tri domobrana $i$ Domobran Jambrek. Upotreba rečce zar u obraćanjima pojedinih oficira njihovim podređenim ima dosta sličnosti kako u pogledu forme rečenice $u$ kojoj se rečca javlja tako i u pogledu uloge koju je ona u obraćanju imala.

\subsection{Obraćanje podređenom}

U Kraljevskoj ugarskoj domobranskoj noveli satnik Jugović obraća se svojim potčinjenim na vežbalištu. On se ponekad obraća grupi vojnika, a ponekad pojedincu iz te grupe. U jednom od tipičnih obraćanja on je nezadovoljan odgovorom koji je upravo dobio na ranije postavljeno pitanje.

[1] - Tko je to „ja sam”? Zar ja moram da vas prepoznajem po glasu? „Ja sam!” Hoću da znadem tko je, a ne „ja sam”! Zar se tako govori sa šefom satnije? ${ }^{8}$ Trkom amo! (Krleža 1982: 48) ${ }^{9}$

U priči Tri domobrana pukovnik Wallenstein obraća se nižem po rangu, kapetanu Ratkoviću. Pukovnik želi nešto da sazna o jednom vojniku:

[2] - Tko je ta svinja - zapitao je gospodin pukovnik gospodina satnika Ratkovića, kao da mu je i on nešto lično skrivio.

8 Pitanje koje počinje rečima zar se tako javlja se u obraćanjima podređenoj osobi dok se ona prekoreva jer se ne ponaša na očekivani način ili što zadatke ne obavlja onako kako se to od nje traži: (1) Zar se tako pred gospodom ponaša?! - kriješti fiškal. (Kovačić 1978: 15) (2) Zar se tako uveče ulazi gospođama? (Matoš 1950: 248); (3) "Zar se tako dočekuje ban i banica?" (Šenoa 1983: 233) Zar se tako straža straži i carsko dobro čuva? (Andrić 1978: 41).

9 I naredni primeri navođeni su prema ovom izdanju. Ime pisca i godina izdanja pritom su izostavljeni. Kurziv u pisanju reći zar dodat je originalnom tekstu. I u primerima iz dela drugih pisaca pisanje reči zar kurzivom dodato je originalnom tekstu. 
- Domobran Račić, gospodin pukovnik, pokorno javljam!

- Pa zar je ta svinja gluha? Zar nije čula zapovijedi? No! Što je! Zašto ne laje? Šta je u civilu taj idiot?

- Tako! Ništa! (188)

Satnik Jugović i pukovnik Wallenstein obraćaju se potčinjenom u prisustvu drugih vojnika, dok se vežba. U primerima vidimo da se rečca zar javila u obraćanju koje sadrži i druga pitanja, uzvike, komentare, naređenja. A stvarni razlog obraćanja sadržan je u rečenici koja se nalazi na kraju. Obraćanje se završilo naređenjem (primer 1), odnosno pitanjem na koje je usledio odgovor (primer 2).

U priči Tri domobrana kapetan Ratković se obraća podređenim u situacijama koje se razlikuju od onih iz prethodnih primera: drugih osoba nema u blizini ili se o njima ne navode obaveštenja. Ali, rečenicama u kojim se javlja zar u njegovim obraćanjima, takođe prethode i slede često druga pitanja, uzvici ili komentari. I u Ratkovićevim obraćanjima podređenom, rečenica $s$ rečcom zar najčešće ima oblik pitanja na koje se ne očekuje odgovor:

[3] - A koji je to vrag, to vaše civilno redarstvo? Vama to imponira, meni ne! [...] Kako to samo stojite pred svojim satnikom? Zar vi ne znate što je bonton? Dajte vi stanite u pozor! (211)

Oficiri Jugović, Ratković i Wallenstein upotrebljavaju rečcu zar u svojim obraćanjima potčinjenim na sličan način. Oni uz zar rečenicu izgovaraju još nekoliko drugih rečenica, uzvika i kraćih izraza. „Zar-rečenica” je obično negde u sredini tog niza. Na kraju obraćanja oficiri saopšte i razlog obraćanja: to je kratko naređenje ili pitanje na koje se čeka odgovor.

\subsection{Prekor, ruženje, uvrede, ispoljavanje besa, psovke, pretnje}

U lingvističkoj literaturi navode se funkcije koje rečca zar ima u tekstu. Udružujući je s drugim rečima govornik želi da izrazi: „iznenađenje pri čemu pitanje prerasta u uzvik, čuđenje sa prekorom, prekor sa primesama saveta, čuđenje sa upozorenjem, molbu" (Mrazović 504).

Rečca zar javila se u rečenicama kojima oficiri prekorevaju vojnike. To je tipična upotreba u pričama Kraljevska ugarska domobranska novela i Tri domobrana. Zadatak nije obavljen, neka radnja se ne izvršava kako pravila 
nalažu. Posle rečenice kojom se izražava prekor ne očekuje se odgovor niti neko objašnjenje. Vojnik bi trebalo da promeni ponašanje, da izvrši postavljeni zadatak na način na koji to oficir očekuje.

[4] - No što je? Zar nećeš da priklopiš desno? - zapiskutao je gospodin satnik [...]. (145)

[5] - Kakav vražji gospodin narednik? Zar je za vas, kadeta, narednik Slepčević gospodin narednik? Vi ste stariji, [...]. Kakve su to gluposti? (50)

[6] - Tako zar? Ha! Je li! I vi to zovete „na rame”? Gdje je tu jedan, dva, tri, četiri? (163)

[7] - Momci! Pazite! Zašto me jadite? Zar nije bolje da živimo u dobru? Pazite, momci! (163)

Ispred rečenice u kojoj se javlja rečca zar govornik često saopšti neku drugu, obično kraću rečenicu ili izgovori neki uzvik. To se vidi i u drugim primerima koji se navode u narednom tekstu. U oficirskim obraćanjima sadržana su naređenja i komentari koji dolaze od čoveka čija bi reč morala bezpogovorno da se sluša. Neke rečenice, međutim, odaju govornika koji se znatno napreže, koji ima osećaj da se ne obraća dovoljna pažnja na to što on govori. Imajući u vidu način na koji se on obraća ljudima koji su mu potčinjeni, moglo bi se reći da je u pitanju čovek koji gubi strpljenje. U Jugovićevom ponašanju, dok se bori za pažnju, izostaje uljudnost pri ophođenju. U jednoj situaciji on pokušava da pridobije vojnike na „lep način”. Taj postupak on sam doživljava kao sopstvenu slabost.

[8] - Gore glavu! Karike do brade! [...] To je da poludiš! Da poludiš! Onaj se tamo migolji! Što je, do vraga? Zar ti stršeni svrdlaju crijevo? (170)

[9] - A što stojite tu tako, kao da se vas to sve ništa ne tiče? Zar vi mislite da nije moguće da ste vi baš onaj koga tražimo? Dajte! (216)

„Zar-rečenice” u formi retorskih pitanja pogodne su za upotrebu u sklopu obraćanja u kojem se javlja više uzvika, komentara i pitanja. Takva rečenica uklopljena u niz od nekoliko rečenica koje čine jedno obraćanje starešine potčinjenom vojniku, dobijala je i posebnu ulogu. Na tom mestu govornik je mogao da pojača izgovor dok upućuje prekor, i da zatim, ne 
praveći pauzu, postavi pitanje na koje traži odgovor, ili da izda neku naredbu. Tako se u Krležinim pričama oficiri obraćaju vojnicima dok ih prekorevaju, ruže i psuju. Ponekad je u pitanju obraćanje pojedincu, a ponekad grupi.

Uz rečcu zar u nekim rečenicama se pojavljuju i imenice svinja, majmun, gad, marva. U uzvicima i kraćim rečenicama koje u jednom obraćanju uslede posle „zar-rečenice” dolaze psovke i uvrede. Pritom se koristi imenice: krava, tele, konj, kobila. (U zbirci priča Hrvatski bog Mars pisac inače koriste izraze koji uključuju „pravo bogatstvo naziva domaćih životinja” (Mikšić 2012: 10) ${ }^{10}$ ).

Primena strategija kojima se teži postizanje uljudnosti: „izbegavanje zapovjednoga tona”, „izbegavanje izravnog obraćanja sugovorniku”, „oklijevanje” (Matešić i Marot Kiš 2016) kada je u pitanju vojnički poziv i sam odnos starešina/vojnik, ograničena je i modifikovana samim pravilima službe. Kao jedan od načina da se postigne uljudnost u ophođenju navodi se i "gomilanje izraza iz poštovanja” (Matešić i Marot Kiš 2016: 113). U oficirskim obraćanjima u pričama iz zbirke Hrvatski bog Mars javljaju se izrazi koji odražavaju nepoštovanje podređenog. U obraćanjima u kojima se javlja rečca zar upotrebljene su i imenice mrcina, lopov, glupan, idiot. Uz prekore i uvrede ponekad su sadržane i pretnje.

[10] - Zar si ti lugar, ti svinjo? (49)

[11] - Tako? U smjeru Jankomira? Ta to je smjer Jarun! [...] Mislite? Je li? Zar mislite da su Čerkezi glupi kao Zagorci? Ovi se lugari španciraju na misu! (50)

[12] - Što je to? Vi mulci prokleti! Zar se bojite jednoga konja? Krave vi bedaste! (78)

[13] - Pajtak! Ti lopov bedasti! Zar nisi ti u trećem? Tele! Falačec! Curiš! Tumbak! Glupani vi! (116)

[14] - Zar još niste gotovi, mater vam božju lijenu bistričku trgnuo se bijesno gospodin satnik. (117)

[15] - Povrat dva je bilo! Zar ne čuješ ti tamo u drugom vodu, majmune? Molim vas, Zvjezdić! Šupite tu gluhu mrcinu! (169)

10 Za takve metafore koje deluju na nivou „dojma i stava” kaže se da im je cilj „ukazivanje na istovjetnost položaja domobrana i stoke koju se odvodi na klanje, ali i naglašavanje njihove naivne, prostodušne i pasivne prirode." (Mikšić 2012: 11). 
[16] - Pa zar taj gad renitentni neće da govori? - izderao se gospodin pukovnik na ovu kreaturu, i sam zbunjen šutnjom ovoga tipa. (189)

[17] - Kohn! Ćušit ću vas! Zar se vi danas šalite? Koji vam je đavo? Bedastiji ste od moje kobile! (207)

[18] - Kohn! Boga vam prevarantskog! Revolver! Zar još nije stavljena ta marva? Mrcine! Pisari! (210)

Oficiri Jugović, Ratković, Wallenstein i Lulić različiti su po rangu, ali u njihovim obraćanjima vojnicima ima dosta zajedničkog. Komandama, naređenjima i drugim saopštenjima koja se neposredno odnose na službu i zadatke koji se vojnicima postavljaju često prethode uzvici, kratki komentari, pitanja na koja se ne očekuje odgovor, uvrede i psovke u vidu uzvičnih rečenica. Rečenica u kojoj se upotrebi rečca zar, dobija posebnu ulogu koja potvrđuje preliminarnu hipotezu navedenu u uvodu rada. Bilo da ima uzvičnu ili upitnu formu, ona može da se izgovori s pojačanom intonacijom. Takva pitanja služe samom govorniku, pokreću ga da govori dalje u skladu sa vlastitim tokom misli (Badurina, Palašić 2018: 393). Ukoliko se između rečenica javlja kraća pauza, ona nije namenjena sabesednikovom odgovoru. On je u tim pauzama izložen psihološki neugodnoj situaciji u kojoj čeka na to šta će govornik još da kaže i kako će dalje da postupi. Ponekad su to pravi izlivi besa u situaciji u kojoj ni udarci nisu isključeni. U pitanju je odnos prema vojniku, obrazac ponašanja koji se uči, prenosi i usvaja kao način postupanja.

\section{Razgovorna situacija}

U priči Domobran Jambrek rečca zar javlja se u opisima razgovora koji se odvija u grupi vojnika. To su obični vojnički razgovori u koje se uključuje i domobran Jambrek. U priči Smrt Franje Kadavera, pored vojnika, pojavljuje se i Kadaverova žena koja koristi rečcu zar dok prekoreva muža koji leži u veneričnoj bolnici. I u priči Hrvatska rapsodija rečca zar javlja se u pitanjima koji su deo običnih razgovora. U razgovoru učestvuju i oni čija se lična imena ne navode, samo se kaže civil, momče, prvi frontaš. Rečca zar dobijala je različite uloge u pojedinim rečenicama u kojima se javljala. Ponekad se razgovara u mirnom tonu, a nekad je u pitanju oštra prepirka u kojoj uz prekore psuje i ruži. 
[19] - Šta? Ništa! Silovali su nas! Izmesarili su nas! Zar nas valjda nisu? Zar nas nisu bacili na cestu? (331)

[20] - A da si vani, zar bi ti bolje bilo? ${ }^{11}$ Uši, mine, voda. (346)

[21] - Pa zar te nije Boga strah? Gromom će te! (356) $)^{12}$

[22] - Glupan! Zar misliš da Bog nema pametnijeg posla, nego da se za takvu marvu brine kao što si ti! (364)

[23] - Zašto nisam ostao? To je moja stvar! A zar misliš da ja ne ću prvim brodom natrag? Samo dok ovaj prokleti rat mine. (372)

[24] Prvi frontaš: A zar ti misliš, tovare behadrajerski da je fronta vašar? (390)

Upotreba rečce zar u opisima razgovora doprinela je da se izraze neslaganja i prepirke. Sam razgovor je važan za situaciju. Tokom njega iskrsavaju prepirke uz koje ponekad dolaze i uvrede. Stiče se utisak da se tema nametnula slučajno. Rečenica u kojoj se javlja zar važna je za opis razgovora, ne za karakterizaciju likova.

\section{5. „Zar-rečenice” u opisima misli i osećanja}

U primerima koji su navedeni u prethodnom tekstu rečca zar javljala se u opisima obraćanja starešine podređenim vojnicima, kao i u opisima razgovora među samim vojnicima. Pored tih uloga u pričama iz zbirke Hrvatski bog Mars rečca zar upotrebljavana je i u rečenicama koje su poslužile opisima stanja pojedinih likova u situacijama u kojima oni, okrenuti sami sebi, preispituju sopstvene postupke i svoje izbore koje čine u strogim ograničenjima koje nameću stroga pravila vojničke službe. U takvim opisima mogu da se koriste pojedini tipovi pripovednih tehnika koje je Dorit Kon nazvala psihonaracija, citirani unutrašnji monolog i pripovedani monolog (Dorrit 1999) ${ }^{13}$.

11 Primere upotrebe izraza zar ne bi bolje bilo izdvojene iz dela drugih pisaca videti u radu (Šolak 2018: 189).

12 Reč je o rasprostranjenoj upotrebi, na primer: „Zar te nije boga strah? (Andrić 1978 knj. 8: 64). Videti i druge primere iz dela drugih pisaca (Šolak 2018: 191).

13 O definicijama i razgraničenjima pojmova unutrašnji monolog, citirani unutrašnji monolog i propovedani monolog s primerima iz svetske i hrvatske književnosti videti takođe i u knjizi Maše Grdešić (Grdešić 2015: 159-195). 
Predstavu o oficirima Jugovića i Ratkovića dopunjuju i „zar-rečenice” kojima se prenosi sadržaj njihovih misli. Dok preispituje sopstveni položaj $\mathrm{u}$ vojsci Jugović sažaljeva samog sebe. A kad mu misli skrenu na vojnike, „zar-rečenice” odražavaju njegov osećaj sopstvene nemoći.

[25] „Eto! Muči se s tom Trinaestom hodnom satnijom punih pet mjeseci [...]. A za koga radi? Zar za sebe? Za narod radi! Za naš mili seljački narod!" (101)

[26] „Eto! I danas! Zar ne bi sad mnogo ugodnije bilo da sjedi do objeda u toploj kavani?" (102)

[27] „Zar ta perfidna banda još nije gotova?” dršće formalno gospodin satnik u sedlu, sav uzrujan, [...]. (116)

[28] „Eto! Holzer je tu sastavio prijavu, a o toj cijeloj stvari ni riječi! [...] To je nečuvena indolencija! Naravna stvar! Zar se ljudi brinu za službu? Glavno je da spavaš cijelu noć!” (260)

[29] - To je glupo! Naravna stvar da je to glupo! I te kako glupo! Ja hoću tu jednoj kabanici, jednoj oficirskoj kabanici da objasnim nešto! Ostrugama! Odurno! Zar sam ja pop? Neka sve vrag nosi! Glupane prokleti! $(267)^{14}$

U naredna četiri primera (30-3) vojnici: Vidović (Baraka pet be), Račić (Tri domobrana), Jambrek (Domobran Jambrek) i Franjo Kadaver (Smrt Franje Kadavera) razmišljaju o situaciji u kojoj se upravo nalaze (prvi i četvrti primer) ili o događajima kroz koje su ranije prošli. U primerima $25 \mathrm{i}$ 26 vidimo da je tekst u kojem se pripoveda u trećem licu postavljen $\mathrm{u}$ navodne znake. Tako je i u primerima 30,32 i $33 .{ }^{15}$

[30] „Zar ga otac njegov pokojni nije tukao? [...] A zar ga razrednik u gimnaziji nije pljuskao?" (249)

[31] „Šta je? Zar sam ja poludio? Kome se ja to molim? [...] Kakvi su to glasovi?” (288)

\footnotetext{
14 Primer je raspoređen u ovu grupu jer su reči kazane „sebi u bradu”. To potvrđuje i naredna replika u kojoj sagovornik kaže: „vi tu nešto buncate”.

15 „Također, zanimljivo je da Krležina pripovjedna proza jedinstvena u hrvatskoj književnosti po tome što je u njoj pripovjedani monolog označen navodnim znakovima, kao da je po srijedi citirani unutarnji monolog." (Grdešić 2015: 186).
} 
[32] „Tamo su negdje izrezali jednu ženu prije sedam godina! [...] A zar njega nisu izmrcvarili!" (331)

[33] „A, eto! Ima pravo! [...] Pa zar će ga ovakav tat ovdje mučiti? Nema pravo!" (375)

\section{Odlike zar rečenice}

U primerima koje smo naveli videli smo da je upotreba rečce zar znatno doprinela karakterizaciji lika, kada su oficiri u pitanju, a kada je reč o vojnicima, da se istakne živost razgovora koje oni vode među sobom. Pored tih uloga u tekstu ona je takođe doprinela i da se opiše opterećenost situacijom u kojoj se nalaze i oficiri i vojnici u čijem se monolozima rečca zar javlja dok preispituju sami sebe i ono što se oko njih zbiva.

Imajući u vidu rečenicu u kojoj je rečca zar upotrebljena, zatim uži kontekst u kojem se takva rečenica javlja, lako se uočava da su u mnogim primerima korišćena i različita pojačanja uz pomoć kojih su i uloge rečce zar potpunije ostvarivane. ${ }^{16}$

\subsection{Pitanja i odgovori}

Retorska pitanja su najčešća forma „zar-rečenice” u zbirci priča Hrvatski bog Mars. Ali, ima i pitanja na koja se očekuje odgovor.

[34] - Zar i ti s dopusta!? ${ }^{17}$

- S dopusta na frontu. (407)

[35] - Kohn! Zar vi niste noćas ovdje spavali?

- Nisam, gospodine satniče, pokorno javljam! (208)

[36] - Vidiš, i to je važno! To je osobito važno! I u Službovniku tako piše! Remen i žniranci se oduzimaju! Još se svinja može objesiti! A to je u Službovniku naročito naglašeno, zar ne?

\footnotetext{
16 Videti Bogdanovićev komentar: „osećanje za reč kod Krleže prerasta u emociju od reči [...] Krležina reč ne ostaje samo sredstvo da se nešto ostvari, već postaje sama sobom jedno ostvarenje, jedan učinak, jedan efekat, jedan estetski trenutak" (Bogdanović 1972: 238).

17 Primer ove rečenice, kao i primere eliptične upotrebe rečce zar izdvojene iz dela drugih pisaca, navedeni su u radu (Šolak 2018: 193).
} 
To su sugestivna, obično „negirana pitanja” na koja „govornik očekuje da slušalac potvrdi zapažanja, pretpostavke govornika" (Mrazović 2009: 506). Mobilisani poručnik doktor Lulić, u priči Domobran Jambrek, obraća se vojnicima s kojima provodi deo slobodnog vremena. Situacija je različita od onih u kojima se aktivni oficiri višeg ranga i položaja, Jugović, Ratković i Wallenstein, obraćaju podređenim. Lulić razgovara s vojnicima. Pokušava da dobije odgovore na neka pitanja. Rečca zar javila se u pitanjima na koja vojnici ponekad odgovore, a ponekad ne. Pitanja odražavaju njegova „izneverena očekivanja” (Janićijević 2017: 248). Situacija se razlikuje i od onih u kojima se, u odsustvu oficira, razgovori vode među vojnicima. U jednoj replici Lulićevo obraćanje postaje tipično za odnos oficira prema vojniku: pitanja i komentari nižu se jedno za drugim. Na kraju je došlo i pitanje na koje su vojnici odgovorili.

[37] - Zar ne da se veselite što ćete u boj? Što?

Stanka. Šutnja. Tišina. (308)

[38] - Pa mater vam domobransku, što je to rat? Zar već nismo bili u ratu? Stotine i stotine godina stojimo u ratu pa smo svejedno živi! Zar ti ćaća i deda nisu bili u ratu?

- E! Bome jesu! Na Taliji su bili! (308)

[39] - Pa zar bi Njegovo Veličanstvo moglo da toliko neprijatelja pobijedi da nije tako bogato? (309)

Posle upotrebe rečce zar u pitanjima na koja se traži odgovor, govornik sačekuje da osoba kojoj je pitanje upućeno nešto kaže. A ukoliko ne stigne odgovor kao u primeru 37, nastaje kraća pauza. U zavisnosti od konteksta u kojem se vodi razgovor, tako se otkrije da među sabesednicima postoji neslaganje i da zbog toga jedna strana ne želi da se izjašnjava. Pri obraćanju govornik uz pitanje nudi i informaciju, zatim očekuje da slušalac odgovori afirmativno. Rečenice sadrže „uverenje o realnosti suprotnog” (Piper i Klajn 2013: 424). Na jedno od retkih pitanja u kojem se rečca zar u sastavu izraza zar ne našla na kraju rečenice (primer 5 na kraju rada u prilogu) čitaocu nije prenet odgovor ili, možda, odgovora nije ni bilo. Pisac o tome ne daje obaveštenja jer za samu priču odgovori natporučnika Holcera pretpostavljenom kapetanu Ratkoviću, nisu od značaja.

\subsection{Upotreba zamenica u „zar-rečenici”}

Ličnu zamenicu ja često upotrebljava satnik Bojanić prilikom obraćanja vojnicima. Tako je u primerima 40-46. Zamenica ja javlja se u istoj rečenici u 
kojoj i rečca zar. Jedan primer „zar-rečenice” u kojoj se javlja i zamenica ja već je naveden (primer 1). Takav je i primer 49. I satnik Ratković upotrebio je ličnu zamenicu ja u „zar-rečenici” (primeri 47 i 48):

[40] - No! Što me gledaš!? Zar me još nikada nisi vidio? Kamo navaljuje satnija? (49)

[41] - No! Što je to? Zar ja uzalud govorim? Jesam li ja vaš gratulant, [...] vi, svinje zagorske? (145)

[42] - Zar ja, misliš, nisam takav mudrijaš kao ti? (220)

[43] - Šta me gledate ovako? Je li? Zar mislite da ja ne vidim da vi mene gledate? Je li? (223)

[44] - A tako? Zar sam ja nitko? Ja sam nitko, je li, to hoćete da kažete? Tako anarhisti misle! Anarhist! Zar mislite da vas „Ja” ne mogu objesiti kao i onoga tamo? (224)

[45] - Straža! Jesi li ti lud, mater ti gluhu? Zar me ne vidiš? (257)

[46] - Zar ću se ja tu prljati? S takvom životinjom? (262)

Lične zamenice $t i$ i vi takođe su u većem broju primera upotrebljene $\mathrm{u}$ istoj rečenici u kojoj su oficiri upotrebili rečcu zar obraćajući se potčinjenim. Satnici Jugović i Ratković i poručnik Lulić upotrebili su zamenicu ti u primerima: $5,8,10,13,15,17,40,51$, a zamenicu vi u primerima: 3,5 , 9, $14,17,34,45,53$. „Zar-rečenice” u kojima su upotrebljene lične zamenice u obraćanjima nadređenog starešine podređenim vojnicima doprinele su opisu same situacije naglašavanjem hijerarhijskog odnosa. Podređeni se podseća na to da bi morao da sluša komande i izvršava naređenja starešine. $\mathrm{Na}$ taj način starešine podsećaju vojnike na to ko je ko i kakve su čije uloge. Rečenice u kojim se javljaju izrazi zar me ne čuješ, zar me ne vidiš, zar nisam rekao, zar sam ja, zar ti ne znaš, zar ti misliš, zar vi mislite, zar vi ne znate, imaju samo formalni oblik pitanja. Kada ih na vežbalištu, obraćajući se vojnicima, izgovara satnik Jugović, stiče se utisak da on ima nekoliko takvih pitanja i da ih često koristi jer je manje-više stalno nezadovoljan onim što u obuci postižu vojnici njegove satnije.

Pokazne zamenice taj, ta u rečenicama u kojima se javlja i rečca zar (primeri 2, 17, 19, 28) u sastavu su izraza kojima se prenose izgovorene reči ili misli oficira (zar je ta svinja: zar taj gad; zar [...] ta marva; zar ta perfidna banda). 
Lične zamenice navođene su i u „zar-rečenicama” u opisima vojničkih razgovora, kao i u opisima razmišljanja u osami, kojem su, poput oficira, skloni i vojnici koje Krleža opisuje. Zamenice ja, on, mi javljaju se u primerima 23, 29, 30, 31, 32 zamenica ti u primerima 19, 20, 21, 23, 40, 51 zamenica mi u primeru 18 i zamenica vi u primeru 48.

\subsection{Upotreba izraza a zar, pa zar}

Pored karakteristika koje su navedene u uvodu rada prilikom osnovnog pregleda javljanja rečce zar u zbirci Hrvatski bog Mars uočen je i znatan broj primera u kojima se ova rečca našla na početku rečenice $u$ sastavu izraza a zar i pa zar. U objašnjenju upotrebe prvog izraza navodi se u literaturi da je tu zar „pojačano partikulom a” (Mrazović 2009: 506). Izraze a zar i pa zar Krleža je postavljao obično na sam početak rečenice. Tako su opisana stanja u kojima jedan lik izražava nevericu, kada su upitanju konačni ishodi promena koji ga lično pogađaju, čuđenje, kada su u pitanju događaji koji su se upravo zbili, neslaganje dok oponira sagovorniku koji ne zapaža nešto što bi moralo da bude svakom očigledno.

Upotrebu izraza a zar videli smo u primerima 25, 26, 32, 34, 53. U primeru 58 satnik Jugović obraćajući se podoficirima postupa blaže nego pri obraćanju vojnicima. Izrazom a zar počinje rečenica kojom se sagovornik u primeru 48 podseća na nešto što bi takođe trebalo uzeti u obzir.

Izraz pa zar dobijao je nešto drukčiju ulogu (primeri 2, 18, 23, 40, 50, 51,52 ). Upotrebljavan je u tipičnim retorskim pitanjima kojima se upućuje prekor ili se na pojačan način izražava čuđenje.

\subsection{Kratke rečenice, par „zar-rečenica”, „zar-rečenice” u nizu}

$\mathrm{U}$ opisima situacija $\mathrm{u}$ kojima vojnici vode razgovor dok borave $\mathrm{u}$ kasarnama, na poligonima dok se obučavaju, dok putuju, kao i u drugim prilikama Krleža je navodeći „zar-rečenicu” obično postavljao ispred nje, a ponekad i posle nje, neki uzvik, kratku rečenicu. To je pogotovo činio u opisu situacija u kojima se oficiri obraćaju vojnicima. Kratkom rečenicom ili uzvikom jedna osoba nastoji da preusmeri pažnju drugih osoba na ono što želi da im saopšti. Ako se obraća nekoj osobi iz grupe, kratkom rečenicom koja može da bude praćena i nekim pokretom ili gestom, govornik najpre daje do znanja na kojeg pojedinca se odnosi ono što upravo namerava da saopšti. Istovremeno, govornik želi da bude siguran u to da će biti saslušan s dovoljnom pažnjom. Takve efekte u jednom obraćanju govornik ponekad 
teži da postigne i upotrebom „zar-rečenica” u paru ili u nizom od nekoliko takvih rečenica. U sledećem primeru iz priče Hrvatska rapsodija dolaze dve „zar-rečenice”, jedna za drugom.

[47] - Hej, vi! Svinjo! Zar ne vidite kako taj jadnik ždere vaše mrvice? Zar vas nije stid? (390)

U primeru 2 u susednim „zar-rečenicama” upotrebljena je rečca zar i izraz pa zar. Tako je i u primerima iz naredne grupe. Obraćajući se vojnicima koji vežbaju satnik Jugović obično u nizu izgovara nekoliko rečenica (primer 48). Prekori i ruženje počinju kratkim rečenicama, uzvicima, slede besmislena pitanja na koja se ne odgovara, uvrede i psovanja. Ako se koriste rečenice u kojim se pojavljuje rečca zar, one su obično uklopljene u taj niz. Njegovoj koheziji doprinosi ponavljanje rečce zar kao i ponavljanje drugih reči. A ako se postavlja neko pitanje na koje se doista traži odgovor, ono dolazi na kraju. $\mathrm{Na}$ sličan način postupa i satnik Ratković (primer 49). Kadaverova žena (poslednji primer), muža koji se leči u vojnoj bolnici za venerične bolesti, ruži na sličan način kao što to čine oficiri dok kore vojnike.

[48] - No! Što me gledaš!? Zar me još nikada nisi vidio? Kamo navaljuje satnija? Pa zar se tako nosi puška u rojnoj pruzi? Zar si ti lugar, ti svinjo? Govori, sto ti bogova, kamo navaljuje satnija? (43)

[49] - Koju stvar? Čovječe božji! Šta je tebi? Pa zar ti živiš na mjesecu? Zar ti ne znaš da je Skomrak provalio u moj stol? Ukrao mi dvije stotine! Na! Tu je jedna od te dvije stotine! (260)

[50] - Ti ovakav, ti onakav! Pa zar tebe ne ždere sram? Zar ti nećeš propasti tu u zemlju? Što si ti to meni naredil? Jesam li ja to od tebe zaslužila? Pfuj te bilo! Ti nisi čovjek, ti si svinja! (379)

Kratke rečenice, uzvici, izrazi pa zar i ponovljena „zar-rečenica”, javljaju se kao različita, kombinovana sredstva pojačanja u tipičnom obraćanju u situaciji u kojoj se jedna osoba prekoreva i ruži drugu. ${ }^{18}$

18 O upotrebi izraza pa zar u delu Ive Andrića, videti: (Šolak 2018: 202-3). 


\subsection{Koncentracija „zar-rečenica”}

$\mathrm{Na}$ dva mesta u priči Kraljevska ugarska domobranska novela uočljiva je koncentracija „zar-rečenica”. Sedam „zar-rečenica” pojavljuju se u priči u blizini jedna druge, već posle nekoliko uvodnih pasusa. One su znatno doprinele opisu situacije u kojoj se nalaze vojnici na vežbalištu i početnoj karakterizaciji glavnog lika, satnika Jugovića, koji je upotrebio „zar-rečenice" koreći vojnike dok im se obraća.

Druga koncentracija rečce zar pojavljuje se u njegovom obraćanju podoficirima. On ih kori, ali se uzdržava od otvorenih uvreda:

[51] - Potčasnici, Domovina! Zar to nije sramota da vi ovako vodite satniju? Zar vi ne znate što znači razviti hod jedne satnije? Zar vi ne znate što je to cilj? Kako treba da se ide na cilj? Zar vama nisu toliko puta rastumačili što je to međucilj? Zar vama sve to nije jasno, potčasnici? Ja ću propasti, eto, propasti, ali ja ću doći na cilj, ako mi se zapovjedi! Pro-pa-sti, ali zapovijed ću ispuniti! A zar vi ne znate, potčasnici, što je zapovijed? Što? Što je zapovijed? (147-8)

U Jugovićevom obraćanju ima dosta reči koje se ponavljaju. Uz rečcu zar, ponavljaju se i reči cilj, zapovijed, potčasnici, satnija, propasti, znati, vi, ja, što. Tri puta javlja se izraz zar vi ne znate. Smenjuju se figure ponavljanja, anafora i epifora. Posebnu pažnju u navedenom obraćanju zaslužuje rečenica izgovorena s uzvičnom intonacijom: Ja ću propasti, eto, propasti, ali ja ću doći na cilj, ako mi se zapovjedi! Oba dela ove rečenice povezane veznikom ali, počinju na isti način: ja ću. Reč cilj pomenuta je u rečenicama koje joj prethode, a reči propasti i zapovijed u rečenicama koje joj slede. U pitanju su složena ponavljanja u kontinuiranom obraćanju jedne osobe grupi osoba. ${ }^{19}$ Prevod je teško mogao da odrazi sve nijanse onoga što je rečeno. ${ }^{20}$

19 U Rječniku stilskih figura Krešimir Bagić uz figuru ponavljanja navodi primer iz priče Tri domobrana uz komentar "figure ponavljanja bogate smisao iskaza, pridonose njegovu zapamćivanju, izrazom slijede opsesivnu misao, izazivaju smijeh, ritmiziraju i segmentiraju iskaz, izdvajaju i naglašavaju ključne reči" (Bagić 2015: 256). Sličan komentar mogao bi da se odnosi i na primer 51 .

20 „Unteroffiziere! Das Vaterland! Ist das nicht eine Schande, daß ihr eine Kompanie so fürtcht? Wißt ihr den nicht, was en 'entwickeln' bei eine Kompanie heißt? Wißt ihr nicht, 
I u priči Tri domobrana koncentracija „zar-rečenica” na strani 112 doprinela je karakterizaciji lika kapetana Ratkovića. U priči Domobran Jambrek sedam javljanja rečce zar grupišu se na dva mesta u priči. Najpre su to četiri „zar-rečenice” u obraćanjima poručnika Lulića na strani 308, a preostala tri, takođe u blizini, pri kraju priče.

Koncentracija „zar-rečenica” takođe je jedan vid pojačanja pomoću kojeg se upotrebom rečce zar postiže poseban efekat u tekstu. Uz taj vid pojačanja Krleža je upotrebio i ona koja smo već objasnili: izraze pa zar i a zar, zatim kratka pitanja i uzvike, kratke rečenice koja prethode rečenici u kojoj se javlja rečca zar.

\section{Karakterizacija lika, živost razgovora, preispitivanje}

Najveći broj upotreba rečce zar u zbirci priča Hrvatski bog Mars javlja se u opisima sadržaja izgovorenih reči u nekoj situaciji. To su pre svega situacije u kojima su se, jedni uz druge, našli ljudi među kojima su odnosi hijerarhijski uređeni, vojnici i njihove starešine. Ako zadatak nije obavljen prema očekivanju, oficiri se obraćaju vojnicima, komandom, naređenjem, zamerkom i prekorom ili pitanjem na koje treba odgovoriti kratko. „Zarrečenice" koje se javljaju u njihovom govoru znatno su doprinele da do izražaja dođu tipične odlike postupanja prema vojnicima u prilikama koje Krleža opisuje. Kada su u pitanju glavni likovi, oficiri Jugović i Ratković, "zar-rečenice" česte u njihovom govoru, pored tipičnog ponašanja, doprinele su otkrivanju ličnih osobina i karakterizaciji tih likova.

Jugović je revnostan oficir koji želi nešto postići. Dok se obraća podređenim on govori s „nekim naročitim apetitom”. On je „vikač iz profesije". Njegovi ukori, pojačani na razne načine, uz čestu upotrebu i ponavljanje istih i sličnih izraza, među kojim ima i uvreda i psovki, postaju prateći deo obuke. Njegove postupke i način obraćanja, pri izlasku na vežbalište, vojnici mogu unapred očekivati. Satnik Jugović ulaže znatne napore kako bi postigao očekivane ciljeve u obuci vojnika, tako da i on postaje žrtva situacije kao što navodi Flaker: „on sam, satnik Jugović, samo dio jedne veće cjeline, jednoga širega stroja kojega je on samo jedna od bezbrojnih poluga" (Flaker 1964: 160). To je čovek kome obavljanje posla

was ein Ziel ist? Wie muß man zu einem Ziel gehen? Hat man euch nicht oft und oft erklßrt, was ein Zwischenziel ist? Ist euch das nicht klar, Unteroffiziere? [...] Und wißt ihr, Unteroffiziere, was ein Befehel ist? (Krleža 1984: 146-7). 
pada kao teško breme. Kapetan Ratković odaje utisak čoveka koji se nije prilagodio vojničkom životu. Upotreba „zar-rečenica” u navođenju njegovih obraćanja podređenom doprinele su opisu impulsivnog ponašanja.

Živost razgovora odlikuje situacije u kojima se razgovara. U pitanju su pre svega razgovori koje u raznim prilikama vode vojnici među sobom, ljudi isti po rangu. Živost razgovora održava se kraćim replikama u kojima ima raznih, i pravih i retorskih, pitanja, među kojima ima i „zar-rečenica”. One su doprinele opisima takvih razgovora koji teku bez zastoja poprimajući ponekad formu prepirke i svađe. Poneka takva rečenica javlja se u opisu razgovora, pri čemu se ništa ne saopštava o govorniku. To je jedna od osoba iz grupe prisutnih.

Preispitivanje je karakteristično za sadržaj misli pojedinih likova, kako oficira Jugovića i Ratkovića, tako i vojnika Jambreka, Račića, Vidovića, Kadavera (primeri 26-34). Upotreba rečce zar u rečenici koja ima formalni oblik pitanja, pogodan je način da se izrazi psihološko stanje osobe koja je okrenuta sama sebi u okolnostima koje su tipične za vojnički život. I oficiri i vojnici, u trenucima osame, nezadovoljni situacijom u kojoj su se našli, dok razmišljaju o onom što se njima i oko njih događa, na sličan način sami sebi postavljaju pitanja na koja ne nalaze odgovore, pitanja pred kojima i sami ostaju začuđeni.

\section{Zaključak}

U zbirci priča Hrvatski bog Mars rečca zar javila se u svega nekoliko primera u upitnoj funkciji u „zar-rečenicama” koje su poprimile oblik pitanja. U većem broju primera rečca zar upotrebljena je u rečenicama koje su zapravo retorska pitanja, na koja odgovora nije ni bilo, niti se očekivao. Jasno su se izdvojile tri uloge rečce zar u takvim rečenicama. Pre svega, ona je u pitanjima posle kojih govornik nastavlja da govori doprinosila karakterizaciji likova kada su u pitanju oficiri u pričama Kraljevska ugarska domobranska novela i Tri domobrana, kapetani Jugović i Ratković. U takvim opisima rečca zar upotrebljena je veliki broj puta što je imalo za posledicu znatnu asimetriju kada su u pitanju druge priče u zbirci.

U pričama Domobran Jambrek, Smrt Franje Kadavera i Hrvatska rapsodija rečenicama u kojima se javlja rečca zar obično se izražava čuđenje, ljutnju i neslaganje sa sagovornikom. Takve rečenice bile su podesne da se $u$ replikama, uz njihovu pomoć, u opisima prepirki u kojima se često protivreči, do izražaja dođe živost razgovora koje vode vojnici. 
Pored uloge u opisima kojim se postiže karakterizacija lika i uloge u opisima vojničkih razgovora, rečca zar, i rečenice u kojima je ona upotrebljena, znatno su doprinele i opisu psihološkog stanja likova u posebnim okolnostima. To su situacije u kojima se kako oficiri, tako i vojnici, osamljeni, prepuštaju mislima i unutrašnjem monologu. U takvim prilikama preispitivanje postaje glavna odlika njihovog ponašanja i psihološkog stanja. „Zarrečenica" pogodan je način da se sadržaj takvog preispitivanja saopšti bilo da je u formi pitanja na koje sledi jednostavan, očekivan odgovor ili, češće, u formi retorskog pitanja pred kojim onaj koji pita ostaje začuđen.

U opisima naglašene hijerarhije u odnosu oficira prema potčinjenima u rečenicama u kojima je upotrebljena rečca zar često se javljaju i lične zamenice. Takve rečenice korišćene su i u opisima vojničkih razgovora $\mathrm{u}$ kojima su neslaganja i oponiranja česta. Krleža je ulogu rečenice u kojoj se javlja zar pojačavao na nekoliko načina: upotrebom izraza a zar, pa zar, kratkim pitanjima koja prethode retorskom pitanju u kojem se javlja rečca zar, navođenjem „zar-rečenica” u paru i nizu, kao i koncentracijom „zarrečenica" navodeći veći broj takvih rečenica u blizini.

\section{Literatura}

Andrić, Ivo (1978) Sabrana dela. Prosveta. Beograd.

Badurina, Lada i Palašić, Nikolina (2018) „Odgovori na pitanja o pitanjima”, Slavistična revija, 66, 3, 383-397. https://srl.si/ojs/srl/article/view/ 2018-3-1-9.

Bagić, Krešimir (2016) Rječnik stilskih figura. Školska knjiga. Zagreb.

Bogdanović, Milan (1972) Kritike. Srpska književna zadruga. Beograd.

Chon, Dorrit (1999) The Distinction of Fiction. The Johns Hopkins University Press. Baltimore.

Gadešić, Maša (2015) Uvod u naratologiju. Leykam international. Zagreb.

Flaker, Aleksandar (1964) „Čovjek i povijest u Krležinim novelama”, Krležin zbornik, ur. Ivo Frangeš i Aleksandar Flaker, Naprijed. Zagreb. 153169.

Janićijević, Mirko (2017) „Realizacija upitnih izraza u biografski usmerenom intervjuu", Srpski jezik u komunikativnoj funkciji, Zbornik radova, Filološko-umetnički fakultet, ur. Miloš Kovačević i Jelena Petković, Kragujevac, 245-258. 
Kovačić, Ante (1978) Fiškal, Među žabarima. Mladost. Zagreb.

Krleža, Miroslav (1984) Der kroatische Gott Mars. prev. Milica SacherMasoch, Reinhard Federmann und Milo Dor, Athenäum. Königstein.

Krleža, Miroslav, Hrvatski bog Mars, eLektire.skole.hr. https://lektire.skole. hr/system/files/pdf/2015/krleza_hrvatskibogmars0.pdf, pristup 20. 06. 2019.

Maretić, Tomislav (1931) Gramatika i stilistika hrvatskoga ili srpskog književnog jezika. Obnova. Zagreb.

Matešić, Mihaela i Marot Kiš, Danijela (2016) „Pragmatika gramatičkih oblika: morfološka i sintaktička sredstva kao načini za iskazivanje uljudnosti", Fluminensia, 27, 2, 103-116.

Matoš, Antun Gustav (1953) Camao, Djela I, JAZU. Zagreb.

Mikšić, Dijana (2012) „Miroslav Krleža, Domobran Jambrek: figurativnost u službi antiratne poruke", Hrvatski, 10, 2, 9-21.

Mrazović, Pavlica (2009) Gramatika srpskog jezika za strance. Izdavačka knjižarnica Zorana Stojanovića Sremski Karlovci. Novi Sad.

Pranjković, Ivo (2012) „Upitno, pojačajno, namjerno i uvjetno li”, Pismo, 12, $10,33-44$.

Piper, Predrag i Klajn, Ivan (2013) Normativna gramatika srpskog jezika. Matica srpska. Novi Sad.

Prins, Džerald (2011) Naratološki rečnik. Službeni glasnik. Beograd.

Vlajić-Popović, Jasna (2016) „Rečca zar - preko sintakse i semantike do etimologije (Zar ti to misliš? $\leftrightarrow$ Ti to misliš zar?)", Južnoslovenski filolog, 72, 1-2, 65-83.

Šenoa, August (1983) Zlatarevo zlato. Sabrana djela, knjiga 1, Globus. Zagreb. Šolak, Zdravko (2018) „Odlike Andrićeve „zar-rečenice”, Umjetnost riječi, 25, 2, 179-207. 


\section{SUMMARY}

\section{Zdravko Šolak}

\section{THE PARTICLE ZAR IN THE STORY COLLECTION CROATIAN GOD MARS BY MIROSLAV KRLEŽA}

In his collection of stories Croatian God Mars, Miroslav Krleža used particle zar 65 times. In the story Battle at Bistrica Lesna, this particle does not appear at all, and its presence in other stories is completely uneven. In some stories there are places of concentration, parts of the text in which several these particles are located close to one another. Particle zar is most commonly used in the description of situations in which one person addresses another one or groups of other people by asking questions that are not expected to be answered. Such questions in Krleža's stories are used by officers while they revile, curse and rebuke soldiers, especially officers Jugović (Magyar királyi honvéd novella / Royal Hungarian Soldier Novel) and Ratković (Three Soldiers). The use of particle zar contributed to the characterization of these officers. Krleža used the same particle in the description of soldiers' conversations. In these descriptions, appearing in the replicas, the particle zar contributed to expressing the conversation vibrancy. Rhetorical questions in which the particle zar appears were also used in the description of the content of internal monologues. Such questions were given an important role in the descriptions of the contemplations, to which both officers and soldiers are subject in moments of solitude, while thinking about their role and their position in the situation in which they presently are.

Key words: particle zar; Miroslav Krleža; Croatian God Mars; dialogue; monologue; lexical repetition 


\section{Prilozi}

Tabela 2. Promene unete u izdanje iz 1962. godine

\begin{tabular}{|c|c|c|}
\hline $\mathbf{r b}$ & Krleža (1946) & Krleža (1962) \\
\hline 1 & Što se bojite jednoga konja? (77) & Zar se bojite jednoga konja? (78) \\
\hline 2 & $\begin{array}{l}\text { Pa šta je ta svinja gluha? Šta nije } \\
\text { čula zapovijedi? (184) }\end{array}$ & $\begin{array}{l}\text { Pa zar je ta svinja gluha? Zar nije } \\
\text { čula zapovijedi? (188) }\end{array}$ \\
\hline 3 & $\begin{array}{l}\text { Šta još nije stavljena ta marva? } \\
(206)\end{array}$ & $\begin{array}{l}\text { Zar još nije stavljena ta marva? } \\
(210)\end{array}$ \\
\hline 4 & $\begin{array}{l}\text { Šta ja, misliš, nisam takav } \\
\text { mudrijaš kao ti? (215) }\end{array}$ & $\begin{array}{l}\text { Zar ja, misliš, nisam takav } \\
\text { mudrijaš kao ti? (220) }\end{array}$ \\
\hline 5 & Šta se ljudi brinu za službu? (255) & Zar se ljudi brinu za službu? (260) \\
\hline 6 & Što ću se ja tu prljati? (257) & Zar ću se ja tu prljati? (262) \\
\hline 7 & Šta sam ja poludio? (285) & Zar sam ja poludio? (288) \\
\hline 8 & $\begin{array}{l}\text { Je li da se veselite, što ćete u boj? } \\
(306)\end{array}$ & $\begin{array}{l}\text { Zar se ne veselite, što ćete u boj? } \\
(308)\end{array}$ \\
\hline 9 & $\begin{array}{l}\text { Pa šta bi Njegovo Veličanstvo } \\
\text { moglo da toliko neprijatelja da } \\
\text { pobijedi, da nije tako bogato? } \\
(307)\end{array}$ & $\begin{array}{l}\text { Pa zar bi Njegovo Veličanstvo } \\
\text { moglo da toliko neprijatelja da } \\
\text { pobijedi, da nije tako bogato? } \\
(309)\end{array}$ \\
\hline 10 & $\begin{array}{l}\text { Šta nas valjda nisu? Šta nas nisu } \\
\text { bacili na cestu? (329) }\end{array}$ & $\begin{array}{l}\text { Zar nas valjda nisu? Zar nas nisu } \\
\text { bacili na cestu? (331) }\end{array}$ \\
\hline 11 & $\begin{array}{l}\text { Pa šta će ga ovakav tat ovdje } \\
\text { mučiti? (374) }\end{array}$ & $\begin{array}{l}\text { Pa zar će ga ovakav tat ovdje } \\
\text { mučiti? (375) }\end{array}$ \\
\hline
\end{tabular}


Tabela 3. Neka izdanja zbirke priča Hrvatski bog Mars u periodu 1933-1990. godine

\begin{tabular}{|r|c|l|l|}
\hline rb & godina & \multicolumn{1}{|c|}{ izdavač } & \multicolumn{1}{c|}{ mesto } \\
\hline 1 & 1933 & Minerva & Zagreb \\
\hline 2 & 1946 & Nakladni zavod & Zagreb \\
\hline 3 & 1948 & Prosveta & Beograd \\
\hline 4 & 1955 & Zora & Zagreb \\
\hline $5^{\circ}$ & 1962 & Zora & Zagreb \\
\hline 6 & 1963 & Svjetlost & Sarajevo \\
\hline 7 & 1967 & Svjetlost & Sarajevo \\
\hline 8 & 1970 & Svjetlost & Sarajevo \\
\hline $9^{*}$ & $1973^{\text {a }}$ & Oslobođenje & Sarajevo \\
\hline 10 & $1973^{\text {b }}$ & Svjetlost & Sarajevo \\
\hline $11^{*}$ & $1973^{\text {c }}$ & Nolit & Beograd \\
\hline 12 & $1977^{\text {a }}$ & Svjetlost & Sarajevo \\
\hline $13^{*}$ & $1877^{\text {b }}$ & Sloboda & Beograd \\
\hline 14 & 1980 & Svjetlost & Sarajevo \\
\hline $15^{*}$ & 1982 & Oslobođenje i Mladost & Sarajevo, Zagreb \\
\hline 16 & 1984 & Veselin Masleša & Sarajevo \\
\hline $17^{*}$ & 1985 & Logos & Split \\
\hline 18 & $1988^{\text {a }}$ & Veselin Masleša & Sarajevo \\
\hline $19^{*}$ & $1988^{\text {b }}$ & Oslobođenje i Mladost & Sarajevo, Zagreb \\
\hline 20 & 1989 & Svjetlost & Sarajevo \\
\hline
\end{tabular}

Napomena: $5^{\circ}$ - izdanje korišćeno u ovom radu, ${ }^{*}$ - izdanja u kojim se rečca zar nalazi na mestima na kojim je i u izdanju $5^{\circ}$. 
SUMMARY

Zdravko Šolak

THE PARTICLE ZAR IN THE STORY COLLECTION CROATIAN GOD MARS BY MIROSLAV KRLEŽA

In his collection of stories Croatian God Mars, Miroslav Krleža used the zar particle 65 times. In the story Battle at Bistrica Lesna, this particle does not appear at all, and it is unevenly distributed in other stories. In some stories there are places of concentration, parts of the text in which several instances of this particle are located close to one another. The particle zar is most commonly used in the description of situations in which one person addresses another person or groups of people by asking questions to which no answer is expected. Such questions in Krleža's stories are used by officers while they revile, curse and rebuke soldiers, especially officers Jugović (Magyar királyi honvéd novella / 'Royal Hungarian Soldier Novella') and Ratković (Three Soldiers). The use of the particle zar contributes to the characterization of these officers. Krleža used the same particle in the description of soldiers' conversations. In these descriptions, when it appears in the conversations, the particle zar contributes to expressing the vivacity of the conversation. Rhetorical questions in which the particle zar appears are also used in the description of the content of internal monologues. Such questions are given an important role in the descriptions of the contemplations, to which both the officers and the soldiers are subject in moments of solitude, while thinking about their role and their position in the situation in which they find themselves.

Key words: particle zar; Miroslav Krleža; Croatian God Mars; dialogue; monologue; lexical repetition 